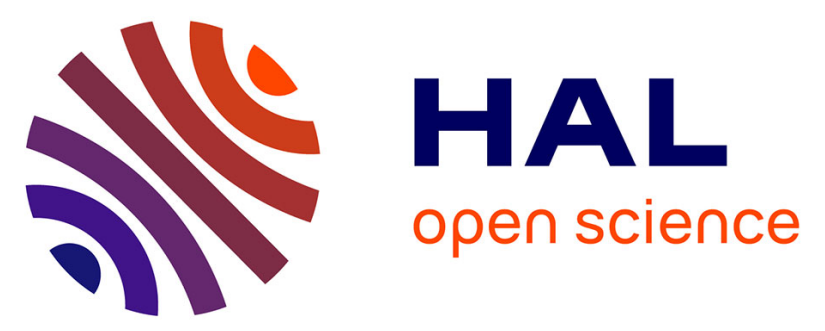

\title{
A tris-oxovanadium pyrogallate complex: synthesis, structure, and magnetic and electronic properties
} Hassan Mkhadder, Morgane Denis, Mónica Giménez-Marqués, Walter

Cañón-Mancisidor, Bernard Humbert, Elise Deunf, Philippe Poizot, Thomas Devic

\section{To cite this version:}

Hassan Mkhadder, Morgane Denis, Mónica Giménez-Marqués, Walter Cañón-Mancisidor, Bernard Humbert, et al.. A tris-oxovanadium pyrogallate complex: synthesis, structure, and magnetic and electronic properties. Dalton Transactions, 2021, 50 (38), pp.13399-13406. 10.1039/d1dt01990b . hal-03428832

\section{HAL Id: hal-03428832 \\ https://hal.science/hal-03428832}

Submitted on 17 Nov 2021

HAL is a multi-disciplinary open access archive for the deposit and dissemination of scientific research documents, whether they are published or not. The documents may come from teaching and research institutions in France or abroad, or from public or private research centers.
L'archive ouverte pluridisciplinaire HAL, est destinée au dépôt et à la diffusion de documents scientifiques de niveau recherche, publiés ou non, émanant des établissements d'enseignement et de recherche français ou étrangers, des laboratoires publics ou privés. 


\title{
A tris-oxovanadium pyrogallate complex: synthesis, structure, and magnetic and electronic properties
}

\author{
Hassan Mkhadder, ${ }^{a}$ Morgane Denis, ${ }^{a}$ Mónica Giménez-Marqués, ${ }^{b}$ Walter Cañón- \\ Mancisidor, ${ }^{c, d}$ Bernard Humbert, ${ }^{a}$ Elise Deunf, ${ }^{a}$ Philippe Poizot, ${ }^{a}$ and Thomas Devic *a \\ a. Université de Nantes, CNRS, Institut des Matériaux Jean Rouxel, IMN, Nantes, France. Email : \\ thomas.devic@cnrs-imn.fr.
}

b. Instituto de Ciencia Molecular (ICMol), c/Catedrático José Beltrán, 2, 46980 Paterna, Spain.

c. Facultad de Ingeniería, Ciencia y Tecnología, Depto. Matemáticas y Ciencias de la Ingeniería, Universidad Bernardo O'Higgins, Chile.

d. Centro de Nanociencia y Nanotecnología CEDENNA, Chile.

\begin{abstract}
With the aim at identifying new cation-phenolate complexes, we here investigated the reactivity of pyrogallol $\left(\mathrm{H}_{3}\right.$ pgal) with vanadium salts. A trimetallic anionic complex was identified, and found to be formed in a broad set of reaction conditions. This complex, formuled $\mathrm{V}_{3} \mathrm{O}_{3}(\text { pgal })_{3}{ }^{3-}$ consists of three oxovanadium(IV) connected together by three pyrogallate ligands to afford a bowl-shaped specie presenting a pseudo 3-fold symmetry axis. Its crystal structure is reported, as well as its characterisation by a broad set of techniques, including powder X-ray diffraction, thermogravimetric analysis, infrared and Raman spectroscopies, and solid state UV-visible diffuse reflectance. Its redox activity both in solution and in the solid state is described, together with its magnetic behavior. Eventually, the relevance of this trimetallic unit in the field of phenolic-based biocoatings and Metal Organic Frameworks (MOFs) synthesis is briefly discussed.
\end{abstract}

\section{Introduction}

Phenolics and their derived coordination complexes are of importance in a variety of fields, including bioinorganic chemistry, soil (de)contamination, cultural heritage, and materials science. For the latter, bio-inspired bulk materials and coatings, notably made of naturally occurring phenolic building blocks, are especially appealing because they combine a high chemical tunability with interesting electronic and mechanical properties, as well as a good biocompatibility. ${ }^{1-3}$ Our physico-chemical understanding of these complex amorphous systems usually relies on the precise chemical and structural information gained from model crystalline molecular complexes. Whereas such a knowledge is rather well established for 1,2dioxobenzenes (catecholates, cat $^{2-}$ ) as well as their oxidised forms (semiquinonate and benzoquinone), ${ }^{4}$ it has been less addressed for the 1,2,3-trioxobenzene (pyrogallate, pgal ${ }^{3-}$ ) unit, although this motif is found in numerous bio-related phenolics. ${ }^{2,5}$

Even if polymetallic entities have been described, ${ }^{6-10}$ catecholate is known to generally favour the formation of monometallic complexes bearing 2 to 3 chelating ligands. In contrast, for pyrogallate, the few reported crystal structures indicate that such a ligand strongly favours the formation of polymetallic entities, each pyrogallate unit being able to easily bind to 2 cations (see Scheme 1). Whatever the oxidation state and the ionic radius of the cation, small, planar and highly symmetric pyrogallol derivatives were found to mostly drive to the formation of infinite chain-like motifs, ${ }^{11-20}$ whereas bulkier ligands presenting a bent 
geometry seem to favour the formation of molecular entities. ${ }^{21-26}$ More precisely, the reactivity of C-alkylpyrogallol[4]arenes or $\mathrm{PgC}_{n}$, (tetra-pyrogallol derivatives) was deeply investigated, notably by Atwood et al. It was found that giant molecular capsules build up from six ligands and triangular trimetallic units could be produced with a broad range of divalent, trivalent and tetravalent cations ( $\mathrm{Mg}(\mathrm{II}),{ }^{27} \mathrm{~V}(\mathrm{IV}),{ }^{28} \mathrm{Mn}(\mathrm{III} / \mathrm{II}),{ }^{24} \mathrm{Fe}(\mathrm{III} / \mathrm{III}){ }^{25} \mathrm{Co}(\mathrm{II}),{ }^{29}$, $\left.\mathrm{Ni}(\mathrm{II})^{26}, \mathrm{Cu}(\mathrm{II}){ }^{22} \mathrm{Ga}(\mathrm{III})^{30}\right)$. The basic coordination motif consists of 3 cations connected together by 3 gallates ligands, all lying roughly in the same plane to define a triangle (see Figure 1). Depending on their nature, oxidation state and surrounding solvent molecules, the cations could adopt either an octahedral or a square pyramidal coordination. As observed in other pyrogallate coordination compounds, ${ }^{14,16,17}$ remaining protons on the meta-oxygen atoms commonly maintain the charge balance. ${ }^{22,27-31}$ Based on the similarities of their crystal structures, it was also initially proposed that the formation of such a coordinative assembly arose from the insertion of cations within a preformed metal-free hydrogen-bonded capsule; ${ }^{22}$ nevertheless, deeper analyses found that such assemblies could also rearrange in solution. ${ }^{26,32}$ To the best of our knowledge, these trismetallic units have never been observed in other compounds than these capsules. We recently showed that when associated with $\mathrm{Zr}(\mathrm{IV})$, pyrogallate derivatives afford a chain-like coordination motif built up from $\mathrm{ZrO}_{8}$ polyhedra for a very broad range of ligands and experimental conditions. ${ }^{15-17}$ In a similar way, we wonder if the afore mentioned triangular units, found with 5 to 6 -fold coordinated cations, are specific to the set of macrocyclic ligands mentioned earlier, or could also be formed with other gallate derivatives, and ultimately be used as a secondary inorganic building unit (SBU) to build up extended coordination networks. ${ }^{33}$ From a materials viewpoint, considering the non-innocent character of phenolate ligands, ${ }^{34}$ such building units could ultimately afford interesting electronic or magnetic properties.

We here first systematically investigated the reactivity of vanadium salts with the simplest pyrogallate derivate, namely pyrogallol. We show that the $\mathrm{V}_{3}(\text { pgal })_{3}{ }^{3-}$ triangular unit is easily formed in a broad set of experimental conditions. The structures of two of these complexes will be presented, together with their redox activities, both in solution and in the solid state. Ultimately, their magnetic behaviour, both in static and dynamic conditions, will be discussed.

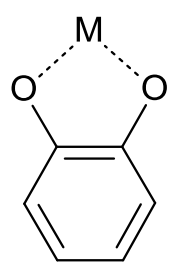<smiles>[M]Oc1c2cccc1O[M]O2</smiles>

Scheme 1. Typical catecholate (left) and gallate (right) coordination motif.

\section{Results and discussion}

\section{Synthesis, structure and spectroscopic characterization}

A survey of the Cambridge Structural Database indicated the existence of a single crystalline compound combining vanadium and pgal, namely a bimetallic complex combining both acetylacetonate (acac) and $\mathrm{H}_{3}$ pgal ligand which was prepared in tetrahydrofuran. ${ }^{35}$ Thanks to a solvothermal high-throughput setup, ${ }^{36}$ the reactivity of pyrogallol $\left(\mathrm{H}_{3}\right.$ pgal) with vanadium salts was here systematically screened in three polar solvents (water, methanol and $\mathrm{N}, \mathrm{N}$ dimethylformamide (DMF)) starting from either $\mathrm{V}(+\mathrm{III})(\mathrm{VCl} 3), \mathrm{V}(+\mathrm{IV})\left(\mathrm{VO}\left(\mathrm{SO}_{4}\right) \cdot \mathrm{H}_{2} \mathrm{O}, \mathrm{VO}(\mathrm{acac})_{2}\right)$ or $\mathrm{V}(\mathrm{V})\left(\mathrm{V}_{2} \mathrm{O}_{5},\left(\mathrm{NH}_{4}\right) \mathrm{VO}_{3}\right)$ at various $\mathrm{pH}$. Only vanadyl acetylacetonate ${ }^{37}$ afforded crystalline solids, both in methanol and DMF. The further optimization of other experimental 
parameters, such as temperature $\left(60\right.$ and $120^{\circ} \mathrm{C}$ for methanol and DMF respectively) and ligand-to-metal-to-base (here aqueous $\mathrm{KOH}$ ) ratio (1:1:2) ultimately yielded samples suitable for single crystal X-ray diffraction (XRD) analyses. Details about the structure determination can be found in Supporting Information (Table S1).

Both compounds, formulated $\mathrm{K}_{3} \mathrm{~V}_{3} \mathrm{O}_{3}(\text { pgal })_{3} \cdot 2(\mathrm{DMF})$ and $\mathrm{K}_{3} \mathrm{~V}_{3} \mathrm{O}_{3}(\text { pgal })_{3} \cdot 4\left(\mathrm{H}_{2} \mathrm{O}\right)$, consist of the same tris-anionic tris-metallic complex built up from three fully deprotonated pyrogallates, and three vanadyl motifs (Figure 1a). While the synthesis performed in DMF lead to a pure DMF solvate, in the case of methanol, structure determination unambiguously indicates the presence of water molecules only, likely coming from the aqueous $\mathrm{KOH}$ solution. Each vanadium is bound to two pyrogallate ligands as well as one terminal oxygen atom, and adopts a square pyramidal coordination. Analyses of the bond distances, as well as bond distances calculations ${ }^{38}$ (see Table S2) indicate a +IV oxidation state for each vanadium ion, in line with the coordination geometry and the presence of terminal vanadyl bonds $(\mathrm{V}=\mathrm{O}$ distances are in the range 1.598(5)-1.618(2) $\AA$ ). Each ligand binds to two $V(I V)$ cations through the standard coordination motif depicted Scheme 1 . This ultimately defines a bowl-shaped complex presenting a pseudo 3 -fold axis, with the three vanadyl bonds pointing outside of

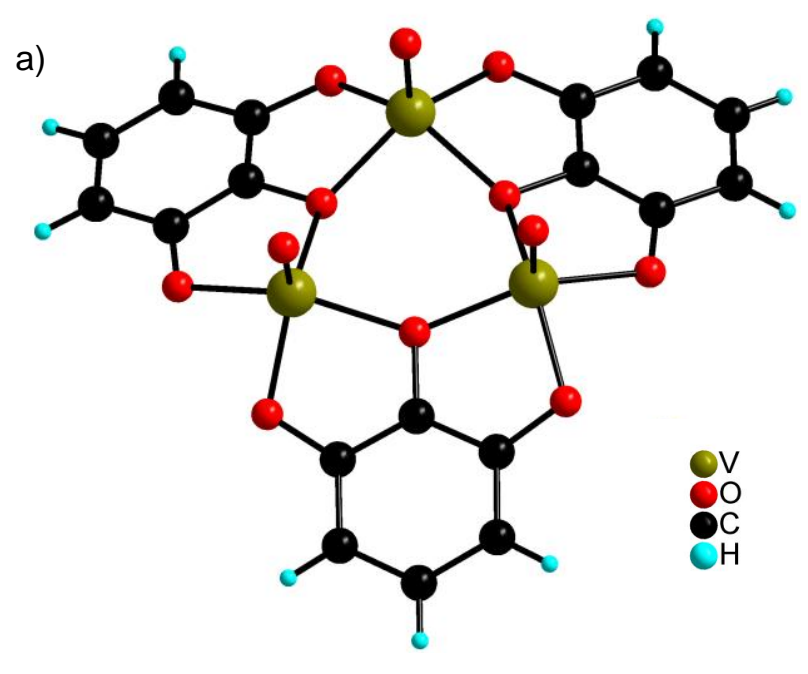

b)

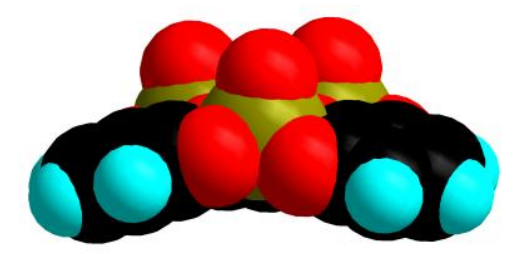

the cavity (Figure $1 b$ ).
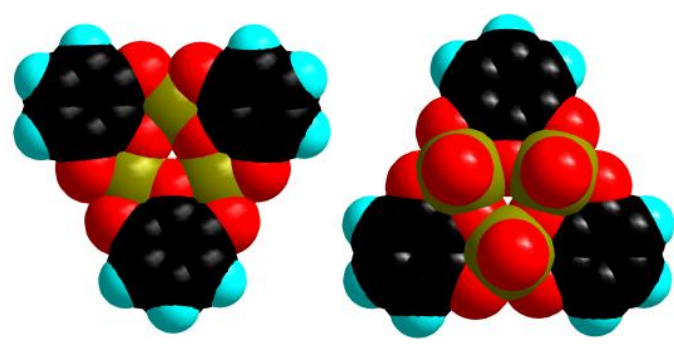

Figure 1. Structure of the $\mathrm{V}_{3} \mathrm{O}_{3}(\text { pgal })_{3}^{3-}$ complex. a) ball and stick representation; b) van der Waals representations, highlighting its bowl-like shape. 
This motif is almost identical to the one observed by Yuan et al. in the capsule $(\mathrm{VO})_{24}\left(\mathrm{PgC}_{n}\right)_{6}$ (ball forms). ${ }^{28}$ Notably, this ball shape is very similar, with a distance between the plane defined

by the 3 aromatic rings and the vanadium atoms lying in the 0.9-1.1 $\AA$ range in both cases (see Figure S4). While in the capsules, the charge balance relies on remaining phenolic protons, ${ }^{22,27-31}$ the structures of both solvates here contain 3 potassium cations per complex. Their presence was confirmed by Scanning Electron Microscopy - Energy-Dispersive X-ray Spectroscopy (SEM-EDXS) analysis, which gives a $V$ to $K$ ratio close to 1 (Figure S7), in accordance with the structure refinement. These cations are weakly interacting with oxygen atoms arising from pyrogallates, vanadyls and solvent molecules (see Table S3 for $\mathrm{K}-\mathrm{O}$ distances and Figure S2). For the DMF solvate, one of the potassium ion (K3) is also involved in a cation- $\pi$ interaction with the pyrogallate ring, ${ }^{39,40}$ as already found in gallate ${ }^{18}$ and pyrogallate ${ }^{41}$ derivatives. A similar feature might occur for potassium ion $\mathrm{K} 2$ in the hydrate, although in an "off-axis" configuration ${ }^{42}$ (see Table S4 and Figure S3).

a)
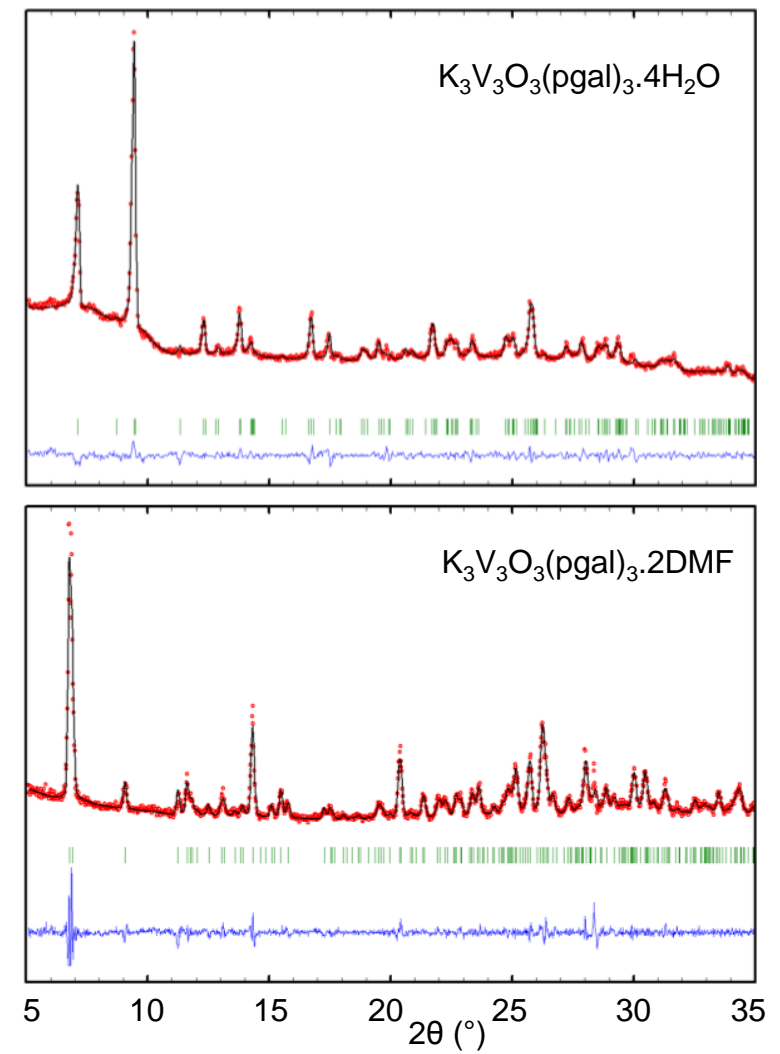

b)

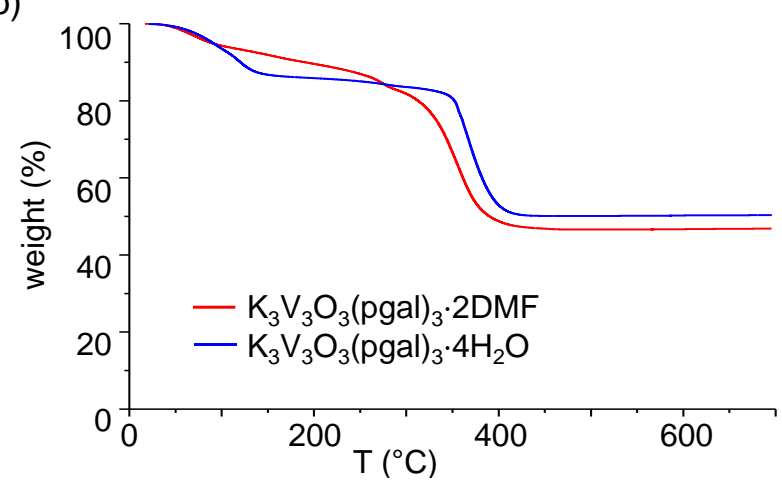

Figure 2. structural and chemical characterizations of $\mathrm{K}_{3} \mathrm{~V}_{3} \mathrm{O}_{3}(\text { pgal })_{3} \cdot 2(\mathrm{DMF})$ and $\mathrm{K}_{3} \mathrm{~V}_{3} \mathrm{O}_{3}(\text { pgal })_{3} \cdot 4\left(\mathrm{H}_{2} \mathrm{O}\right)$. a) X-ray powder diffraction patterns: structureless pattern refinements (red: experimental; black: 
calculated; blue: difference; green: position of the Bragg peaks); b) thermogravimetric analyses performed under $\mathrm{O}_{2}$ (heating rate $5^{\circ} \mathrm{C} \mathrm{min}^{-1}$ ).

The experimental X-ray powder diffraction (XRPD) patterns of both compounds are shown Figure 2a. Structureless (Lebail) pattern refinement lead to cell parameters almost identical to those extracted from the single crystal XRD experiments (see Table S1), indicating that both phases were produced in a pure form. Both compounds were also analyzed by thermogravimetric analyses carried out under oxygen (Figure $2 \mathrm{~b}$ ). After a first weight loss at low temperature $\left(<200^{\circ} \mathrm{C}\right)$ associated with solvent departure, the full combustion occurred at $300-350^{\circ} \mathrm{C}$ to eventually afford oxides containing $\mathrm{V}(\mathrm{V})$ and $\mathrm{K}(\mathrm{I})$. The experimental weight losses, both for the low temperature (desolvation) and high temperature (combustion) plateaus match well with the ones calculated from the proposed formula (see Table S5 for details), confirming that both solvates could be produced in a pure form.
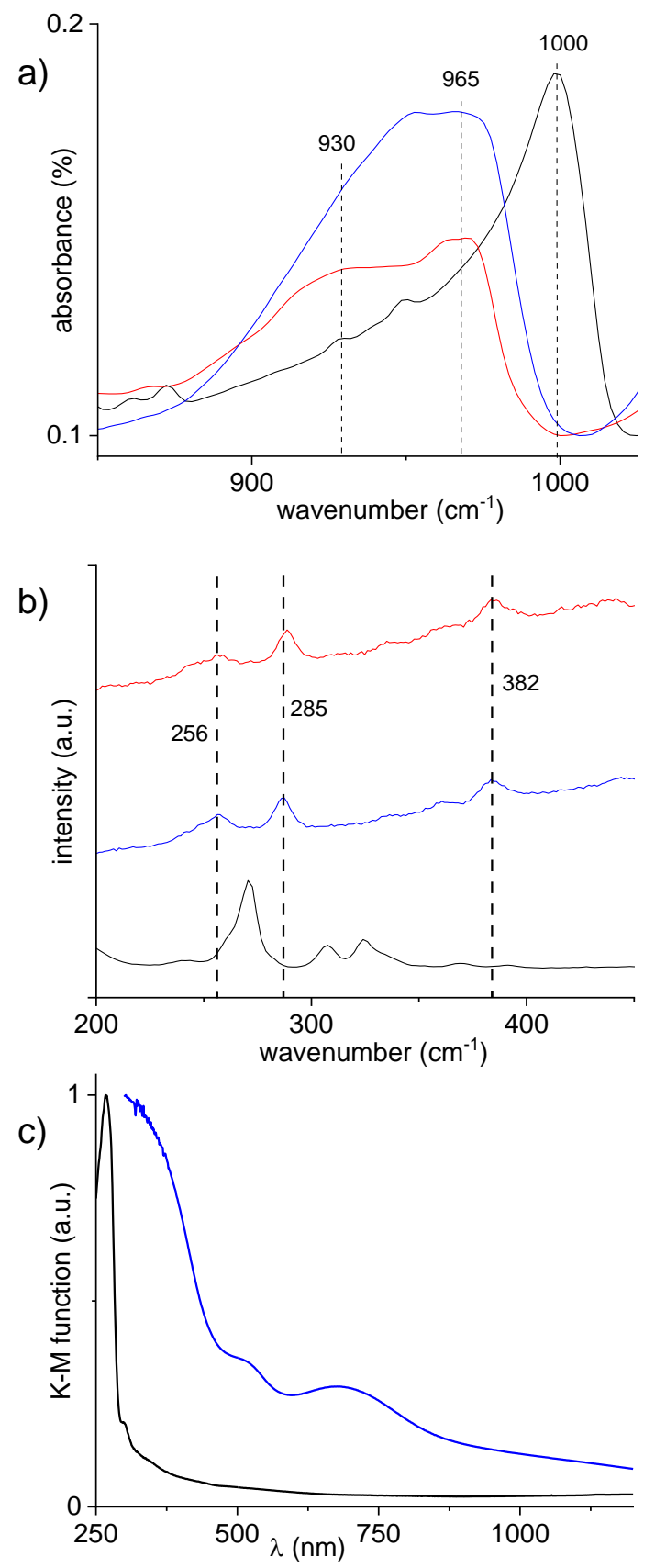
Figure 3. Spectroscopic characterizations of $\mathrm{K}_{3} \mathrm{~V}_{3} \mathrm{O}_{3}(\text { pgal })_{3} \cdot 2(\mathrm{DMF})$ (red) and $\mathrm{K}_{3} \mathrm{~V}_{3} \mathrm{O}_{3}(\text { pgal })_{3} \cdot 4\left(\mathrm{H}_{2} \mathrm{O}\right)$ (blue), as compared to the free ligand $\mathrm{H}_{3}$ pgal (black). a) Infrared spectra (inset: zoom in the 900-1000 $\mathrm{cm}^{-1}$ region); b) Raman spectra upon irradiation at $785 \mathrm{~nm}$; c) UV-vis solid state reflectance spectra.

Both compounds were further characterized spectroscopically. Infrared spectroscopy (Figure S5) first confirmed that free pyrogallol is absent in the final products. Furthermore, the presence of strong bands at ca. $970-930 \mathrm{~cm}^{-1}$ (Figure 3a) is indicative of the presence of $\mathrm{V}=\mathrm{O}$ bonds $\left(\mathrm{V}=\mathrm{O}\right.$ vibration band expected in the range $\left.930-1030 \mathrm{~cm}^{-1}\right), 37,43,44$ although an overlap with a band belonging to the ligand cannot be totally ruled out. Raman spectra were also collected, both in the ranges 1720-620 and 1260-60 $\mathrm{cm}^{-1}$, with the final aim at identifying bands specific to the triangular $\mathrm{V}_{3} \mathrm{O}_{3}$ (pgal) $)_{3}$ motif. Contrary to pyrogallol alone, both complexes were found to be very beam-sensitive upon irradiation at 514 and $633 \mathrm{~nm}$; only an irradiation at $785 \mathrm{~nm}$ afforded reasonably stable signals. At low wavenumber (Figure $3 \mathrm{~b}$ ), bands at 382, 285 and $256 \mathrm{~cm}^{-1}$ which are not visible for the free ligand, were found in both compounds; the first one can be tentatively be assigned to the $\mathrm{V}-\mathrm{O}$ vibration while the other ones might be associated with deformation modes. ${ }^{45}$ At higher wavenumber (Figure S6), a strong peak centered at $970 \mathrm{~cm}^{-1}$ was observed in both solvates and was attributed to the $\mathrm{V}=\mathrm{O}$ vibration

Solid state UV-vis reflectance spectroscopy of $\mathrm{K}_{3} \mathrm{~V}_{3} \mathrm{O}_{3}(\text { pgal })_{3} \cdot 4\left(\mathrm{H}_{2} \mathrm{O}\right)$ evidenced the presence of two absorption bands centered at ca. 500 and $680 \mathrm{~nm}$ (broad), which are absent from the spectrum of $\mathrm{H}_{3}$ gal (Figure $3 \mathrm{c}$ ). These absorption bands fall in the expected range for oxovanadium(IV)-phenolate complexes, ${ }^{46}$ and are likely related to both $\mathrm{d}$ - $\mathrm{d}$ transitions and ligand-metal charge transfer.

To summarize, all spectroscopic characterizations are in good agreement with the structure extracted from the single crystal analysis, and the assignment of the oxidation state of the cation and the ligand.

\section{Electrochemical properties}

As both the organic gallate derivative ${ }^{47}$ and the vanadium cation a priori hold a redox activity, the electrochemical properties of the title solids were investigated, initially in the solid state. Although numerous studies have already evidenced the rich electrochemistry of vanadium phenolates complexes in solution in line with the non-innocent character of this family of ligands, ${ }^{43,48-54}$ to the best of our knowledge no electrochemical probing in the solid state is available to date. The hydrated complex was first dried at $120^{\circ} \mathrm{C}$ under vacuum to get the corresponding anhydrous $\mathrm{K}_{3} \mathrm{VO}_{3}(\text { pgal })_{3}$ phase prior to assess its electrochemical behavior in $\mathrm{Li}$ half-cell by using $1 \mathrm{M} \mathrm{LiPF}$ in a 1:1 mixture of ethylene carbonate $(E C)$ and dimethylcarbonate (DMC) as the electrolyte (see Supporting Information for details). Considering the potential dual redox-activity of the vanadium(IV) phenolate complex, two potential windows were evaluated both in the anodic $\left(2.5 \leq E \leq 4 \mathrm{~V}\right.$ vs. $\left.\mathrm{Li}^{+} / \mathrm{Li}\right)$ and in the cathodic region $(1.0 \leq E \leq$ $3.0 \mathrm{~V} \mathrm{vs}$. $\mathrm{Li}^{+} / \mathrm{Li}$ ). The corresponding galvanostatic cycling data are shown in Figure $4 \mathrm{a}$. 
Upon oxidation (plain line), a continuous event spanning from 3.4 to $4.0 \mathrm{~V}$ is observed, with an inflection point at $\approx 3.7 \mathrm{~V}$. This oxidation trace involves 4 electrons per trimeric unit (i.e., 1.3 electrons per $\mathrm{V}$ ) and could thus be tentatively attributed to the oxidation of both $\mathrm{V}(\mathrm{IV})$ cations and pyrogallate moieties. Considering the equilibrium redox potential of $\mathrm{Li}^{+} / \mathrm{Li}^{(-3.04}$ $V$ vs. NHE), this oxidation potential rather matches with those measured in solution for square pyramidal oxovanadium-phenolate complexes. ${ }^{54,55}$ Nevertheless, this oxidation is found to be poorly reversible upon further reduction and cycling. Scanning a narrower potential range $\left(2.8-3.7 \mathrm{~V} v s\right.$. $\left.\mathrm{Li}^{+} / \mathrm{Li}\right)$ to possibly address a single redox event leads to a reduced number of electrons exchanged $(\approx 1.5$ per trimeric unit) but without any improvement of the reversibility (Figure S8). Starting by the cathodic side (Figure 4a, dashed line), a single event located at $\approx 1.5 \mathrm{~V} \mathrm{vs.} \mathrm{Li}^{+} / \mathrm{Li}$ is detected, and associated with 1 electron exchanged per trimeric unit. Although occurring at a rather low potential, this reduction might be related to the $\mathrm{V}(\mathrm{IV}) / \mathrm{V}$ (III) redox couple. ${ }^{54}$ Similarly to the anodic study, the electrochemical behavior in reduction was found to be irreversible, precluding the use of this compound as active electrode materials for the electrochemical energy storage. A postmortem inspection of the electrodes evidenced the solubilization of the material, which could at first sight be attributed to its molecular (rather than polymeric) character, and
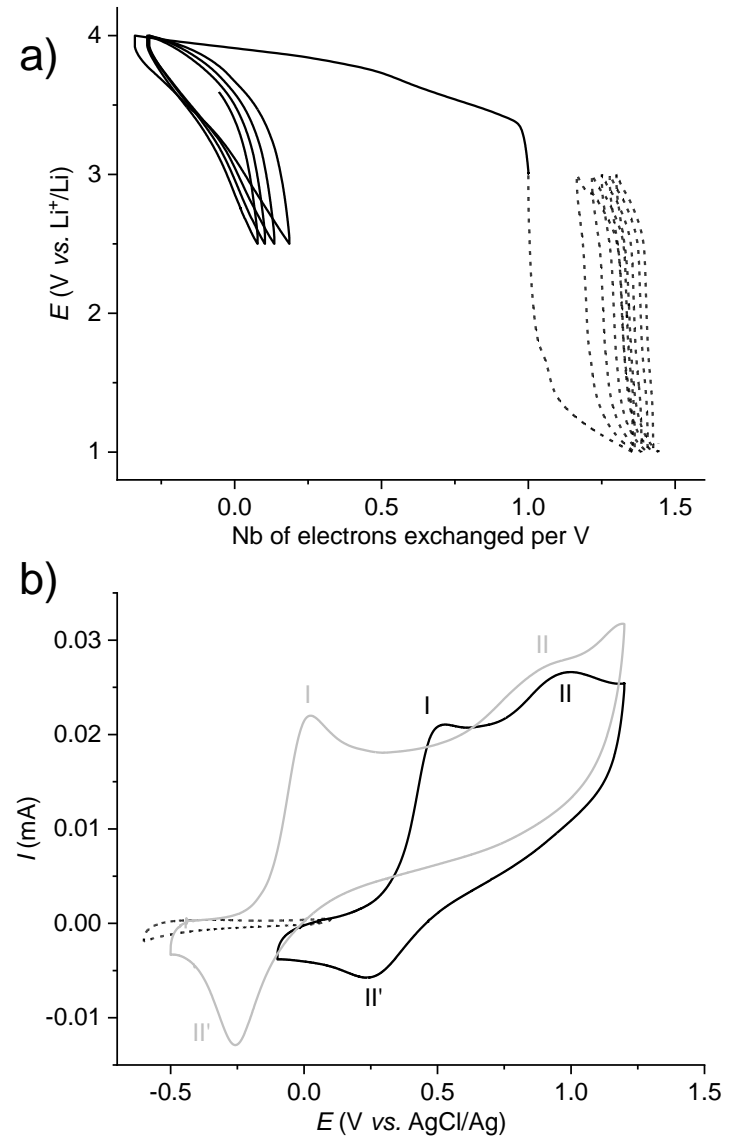

explains such an irreversibility as a logical consequence.

Figure 4. Electrochemical behavior of $\mathrm{K}_{3} \mathrm{VO}_{3}(\mathrm{pgal})_{3}$. a) Measured in the solid state (anhydrous phase) vs. Li by using a galvanostatic method; plain line: anodic region; dashed line: cathodic region (electrolyte: $1 M \mathrm{LiPF}_{6}$ in EC/DMC, cyclic rate: $\mathrm{C} / 10$ ). b) Measured in aqueous solution by $\mathrm{CV}$ in the dissolved state at $\mathrm{pH} \approx 4-5$ upon oxidation (plain line) and reduction (dashed line); grey: after the addition of 10 equivalents of trimethylamine $(\mathrm{pH} \approx 11)$ (electrolyte: $\left.1 \mathrm{M} \mathrm{NaClO}_{4}\right)$. 
To determine whether this solubilization is the sole source of irreversibility, complementary electrochemical investigations by cyclic voltamperometry (CV) were performed in aqueous solution (electrolyte: $1 \mathrm{M} \mathrm{MClO}_{4}, \mathrm{M}=\mathrm{Li}, \mathrm{Na}$ ), where both complexes are soluble. Both solvates were studied by cyclic voltammetry between -0.6 and $1.2 \mathrm{~V} v \mathrm{v}$. $\mathrm{AgCl} / \mathrm{Ag}$ (see Figure S9). As they present similar electrochemical traces, only the hydrate will be discussed (Figure 4b). Experiments were first performed at the natural $\mathrm{pH}(\approx 4-5)$. No event is detected in reduction, while two oxidation waves are observed at ca. 0.5 and $0.98 \mathrm{~V} \mathrm{vs}$. $\mathrm{AgCl} / \mathrm{Ag}$. Considering the equilibrium redox potential of the $\mathrm{AgCl} / \mathrm{Ag}$ reference electrode $(0.205 \mathrm{~V} v$ s. $\mathrm{NHE}$ ), these potentials are rather in line with those observed in the solid state, and hence attributed to the oxidation of both the ligand and the cation. Upon addition of an excess of base (here trimethylamine), the first oxidation I is strongly downshifted to $0.02 \mathrm{~V}(\Delta \mathrm{E}=0.48$ $\mathrm{V})$, while the one at high potential (II) is less affected $(\Delta \mathrm{E}=0.10 \mathrm{~V})$, suggesting that proton transfer is involved at least in the first process (Figure $4 \mathrm{~b}$ ). In all cases, both processes were found to be irreversible, suggesting that the title complex is intrinsically unstable upon oxidation.

\section{Magnetic properties}

The magnetic properties of the title complex were investigated. Static magnetic measurements $(\mathrm{dc})$ were first performed on crystals of a fresh sample of $\mathrm{K}_{3} \mathrm{~V}_{3} \mathrm{O}_{3}(\text { pgal })_{3} \cdot 4\left(\mathrm{H}_{2} \mathrm{O}\right)$ in $\mathrm{MeOH}$ from 2 to $300 \mathrm{~K}$ under a magnetic field of $1000 \mathrm{G}$. Data are shown in Figure $5 \mathrm{a}$. The room temperature $\chi_{\mathrm{M}} \mathrm{T}$ value of $1.09 \mathrm{~cm}^{3} \cdot \mathrm{K} \cdot \mathrm{mol}^{-1}$ (where $\chi_{\mathrm{M}}$ is the molar magnetic susceptibility) is close to the expected value of $1.08 \mathrm{~cm}^{3} \cdot \mathrm{K} \cdot \mathrm{mol}^{-1}$ for 3 non-interacting V(IV) centers with a $g=1.97,{ }^{56}$ hence in full agreement with the structural and spectroscopic analyses. This value is continuously increasing upon decreasing temperature reaching a maximum of $1.50 \mathrm{~cm}^{3} \cdot \mathrm{K} \cdot \mathrm{mol}^{-1}$ at $7 \mathrm{~K}$ and subsequently decreases sharply to $1.11 \mathrm{~cm}^{3} \cdot \mathrm{K} \cdot \mathrm{mol}^{-1}$ at $2.0 \mathrm{~K}$. The increase of the $\chi_{M} T$ value upon reduction of the temperature indicates the existence of ferromagnetic interactions between the $\mathrm{V}(\mathrm{IV})$ centers. This is in agreement with the Magnetization (M) versus field $(\mathrm{H})$ studies at $2 \mathrm{~K}$ (inset of Figure 5 ), which show a nearly saturated value equivalent to 2.6 electrons under a maximum field of $50 \mathrm{KOe}$. Then, on the basis of the structure arrangement of the V(IV) triangles, a model considering isotropic exchange interactions $J$ for an equilateral triangle was considered using the Hamiltonian ${ }^{57}$

$\widehat{H}=-2 J\left(S_{1} S_{2}+S_{1} S_{3}+S_{2} S_{3}\right)+\mu_{B} g H \sum_{i=1}^{3} \hat{S}_{i}$

The best fit parameters including a secondary intermolecular interaction $z J^{\prime}$ show a ferromagnetic exchange interaction $J=+4.92$ (9) $\mathrm{cm}^{-1}$ occurring between the $V(I V)$ centers and an antiferromagnetic intermolecular interaction among molecules of $-0.15 \mathrm{~cm}^{-1}(\mathrm{~g}=$ 1.97). The ferromagnetic nature of the $J$ value is in agreement with the previous studies carried out on the capsule system made of $\mathrm{PgCn}$ containing related trimeric units, as expected for similar magnetic exchange pathways. ${ }^{28}$ In the present molecular system, this exchange interaction may be also influenced to some extent by the presence of the $\mathrm{K}^{+}$ions that interact with the oxygen of the vanadyl unit, which are known to affect the overlap between the magnetic ions $(\mathrm{V}(\mathrm{IV}))$, by tuning the interaction between them. ${ }^{58}$

Dynamic magnetic measurements (ac) in the absence of an external dc field show the absence of an out-of-phase signal, $\chi^{\prime \prime}$ (Figure S11), as previously reported in the capsule-like material. ${ }^{28}$ However, further investigation of the dynamic response upon the application of different dc fields (500-6000 G) revealed frequency-dependent signals in the out-of-phase. 

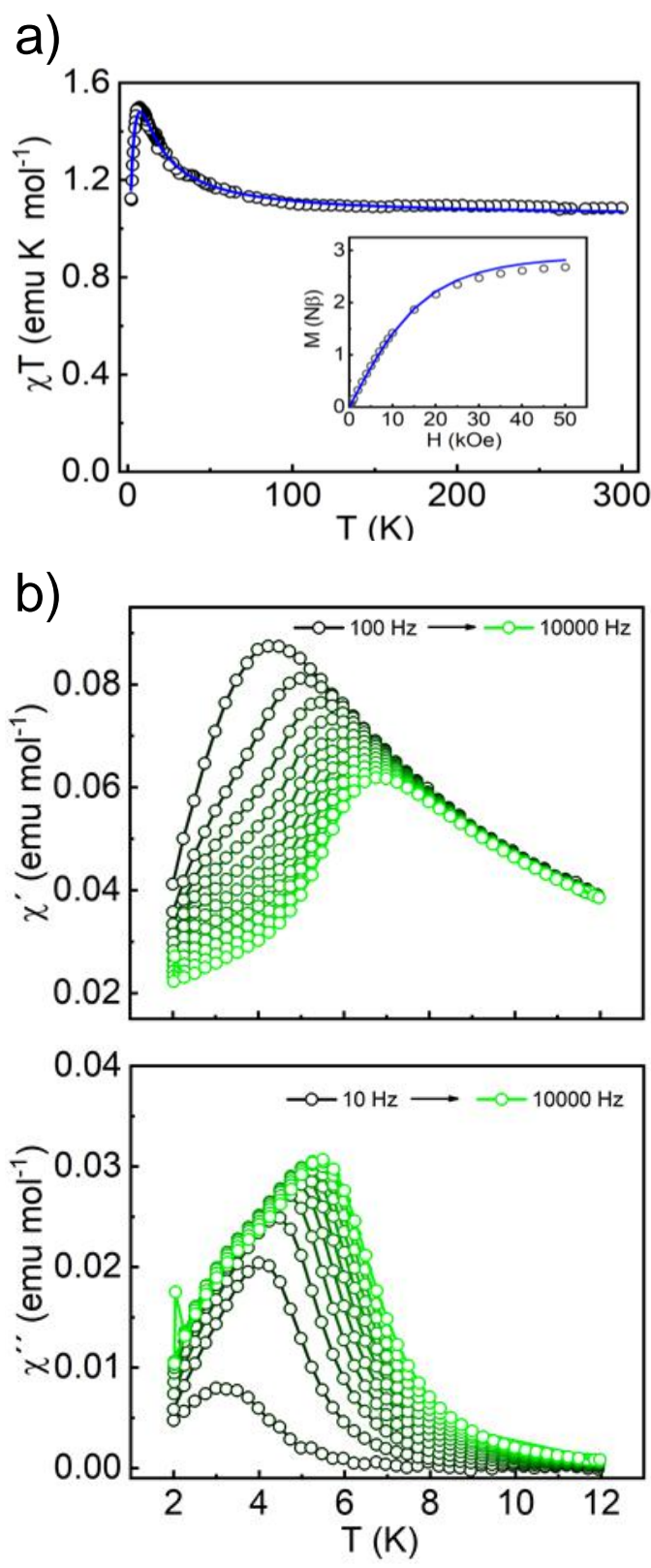

Figure 5. Magnetic behavior of $\mathrm{K}_{3} \mathrm{VO}_{3}(\mathrm{pgal})_{3} \cdot 4 \mathrm{H}_{2} \mathrm{O}$. a) Thermal dependence of $\chi_{M} T$ at $1000 \mathrm{G}$ between 2 to $300 \mathrm{~K}$, with the curve for the best fit parameters obtained considering the equation above. Inset, $\mathrm{M}(\mathrm{H})$ plot at $2 \mathrm{~K}$ with the calculated magnetization curve using the same Hamiltonian; $b$ ) ac susceptibility $\left(\chi^{\prime}(T)\right.$ and $\left.\chi^{\prime \prime}(T)\right)$ measurement at different frequencies under an applied dc magnetic field of $6000 \mathrm{G}$.

This is possibly due to the presence of a fast relaxation of the magnetisation through a quantum tunnelling mechanism that can be easily removed with the application of an external dc field that drives the levels away from the hyperfine avoided crossing region causing the magnetic uniaxial anisotropy in this system. ${ }^{59}$ Examination of the field dependence of the compound suggests that a high dc field of 6000 or $5000 \mathrm{G}$ is required to exhibit both $\chi^{\prime}$ and $\chi^{\prime \prime}$ slow relaxation and a maximum which is frequency dependent (see Figure S11), as observed for other triangular systems. ${ }^{60}$ The relaxation dynamics were then investigated considering different possible mechanisms, the Orbach process and separately, the Raman + direct relaxation mechanism. ${ }^{61,62}$ Figure 6 depicts the temperature dependence 
of the relaxation time, log $(t(s))$ vs $\log (T(K))$, of the ac magnetic susceptibility data measured at two fields $(5000$ and $6000 \mathrm{G}$ ), considering the two processes independently. It can be observed that the Orbach mechanism permits to fit the experimental data in all the temperature range (Figure 6a). On the contrary, the analysis of the relaxation dynamic regarding the Raman + Direct model permits to fit the experimental data in the high temperature range, observing deviations of the fitting curve at low temperature (Figure 6b). The best fit parameters considering the Orbach mechanism result a Ueff $=15.23(55) \mathrm{cm}^{-1}$ with $t_{0}=2.21(31) \times 10^{-7} \mathrm{~s}$ at $5000 \mathrm{G}$ (see Table S5). Therefore, it appears that Orbach mechanism is the one that more correctly describes the relaxation dynamics of this system. However, this derived barrier is also consistent with the two $S=1 / 2$ excited exchangecoupled levels (both at $\Delta \mathrm{E}=3 \mathrm{~J}$ ), which would support the interpretation of relaxation occurring via excited exchange-coupled states rather than via the anisotropy barrier as usually observed
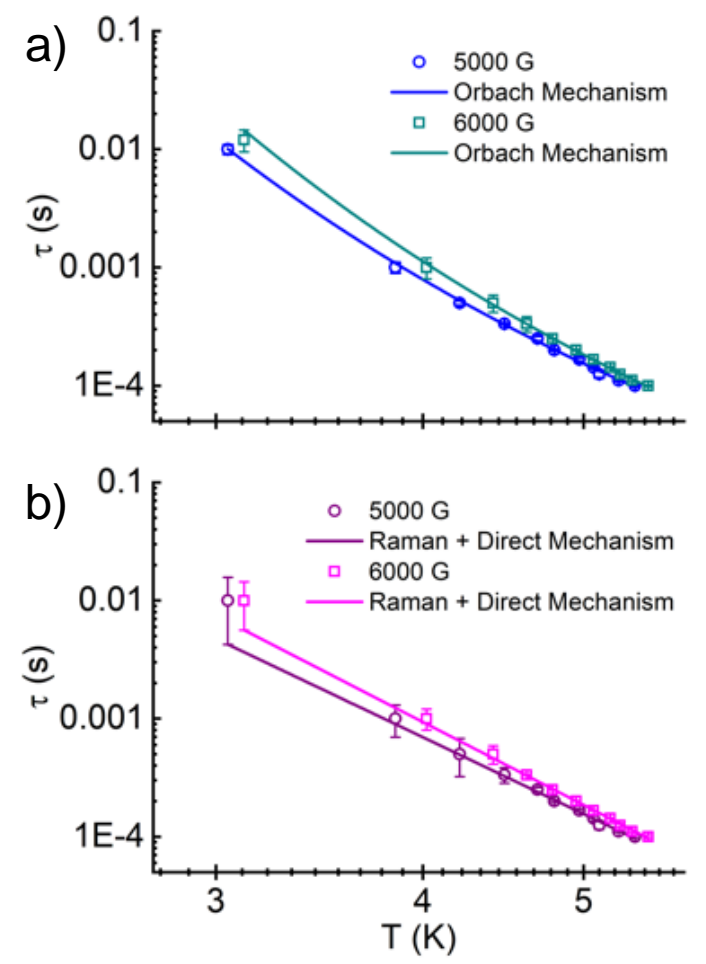

in Single Molecule Magnets, therefore concluding that additional experiments are required to better describe the relaxation mechanism.

Figure 6. Temperature dependence of the relaxation time of the magnetic susceptibility measured in at 5000 and $6000 \mathrm{G}$ for the of $\mathrm{K}_{3} \mathrm{~V}_{3} \mathrm{O}_{3}(\text { pgal) })_{3}$ considering the Orbach (a) and Raman + direct (b) mechanism.

\section{Conclusions}

We here described the synthesis of a new trismetallic vanadium complex, its structural and spectroscopic characterization, as well as its electrochemical and magnetic behaviors; notably, this motif was found to exhibit intramolecular ferromagnetic interactions. The formation of polymetallic vanadium complexes is usually very condition dependent. ${ }^{63}$ Here, we found that the combination of the gallate unit and V(IV) leads easily to the formation of the title complex, not only with pyrogallol[4]arene as already reported, ${ }^{28}$ but also with the simplest pyrogallate derivative. This trimetallic complex even appears rather robust, as it is formed in different experimental conditions (solvent, temperature), and can isolated both in the neutral (protonated) ${ }^{28}$ and anionic (deprotonated) forms. It seems thus reasonable to 
postulate that such a trimetallic unit might also be present in amorphous coordination coatings made from gallate derivatives, especially when vanadium is used; ${ }^{64}$ our spectroscopic data might help to identify this motif in such complex mixtures. Eventually, the $\mathrm{V}_{3} \mathrm{O}_{3}$ (pgal) $)_{3}$ unit also appears as a new potential molecular secondary building unit (SBU) for the construction of extended magnetic coordination networks. Whereas many SBU based on carboxylate ligands have been identified and used for the construction of extended networks, ${ }^{33}$ phenolate ligands and polymetallic entities are extremely rare, although they offer clear benefits in term of chemical stability, effective magnetic interactions or redox properties. ${ }^{7-10,16}$ Such investigations are currently under way in our laboratory.

\section{Acknowledgements}

Funding (fellowships for M.D and H.M) from the region Pays de la Loire (project PSR 'MatHySE2') is acknowledged. The authors also thank the synchrotron Soleil for providing access to the beamline Cristal Soleil, as well as the network Reciprocs. P. Fertey is thanked for this help during the measurement and G. Mouchaham for fruitful discussions. N. Stefan and S. Grolleau are thanked for the SEM and TGA analyses respectively. M.G.-M. thanks support from Generalitat Valenciana (SEJI2020/036), "la Caixa" Foundation (LCF/BO/PI19/11690022) and Spanish MINECO for a Ramón y Cajal Contract (RYC-2019-027902-I). W.C.M acknowledge basal project AFB180001.

\section{Notes and references}

1 M. A. Rahim, S. L. Kristufek, S. Pan, J. J. Richardson and F. Caruso, Angew. Chem. Int. Ed., 2019, 58, 1904-1927.

2 M. Shin, E. Park and H. Lee, Adv. Funct. Mater., 2019, 29, 1903022.

3 M. Björnmalm, L. M. Wong, J. P. Wojciechowski, J. Penders, C. C. Horgan, M. A. Booth, N. G. Martin, S. Sattler and M. M. Stevens, Chem. Sci., 2019, 10, 10179-10194.

4 C. G. Pierpont, Inorg. Chem., 2011, 50, 9766-9772.

5 S. Quideau, D. Deffieux, C. Douat-Casassus and L. Pouységu, Angew. Chem. Int. Ed., 2011, 50, 586-621.

6 T. J. Boyle, L. J. Tribby, T. M. Alam, S. D. Bunge and G. P. Holland, Polyhedron, 2005, 24, $1143-1152$.

7 S. Leubner, V. E. G. Bengtsson, A. K. Inge, M. Wahiduzzaman, F. Steinke, A. Jaworski, H. Xu, S. Halis, P. Rönfeldt, H. Reinsch, G. Maurin, X. Zou and N. Stock, Dalton Trans., 2020, 49, 3088-3092.

8 R. Matheu, E. Gutierrez-Puebla, M. Á. Monge, C. S. Diercks, J. Kang, M. S. Prévot, X. Pei, N. Hanikel, B. Zhang, P. Yang and O. M. Yaghi, J. Am. Chem. Soc., 2019, 141, 17081-17085.

9 M. P. M. Poschmann, H. Reinsch and N. Stock, Z. Anorg. Allg. Chem., 2021, 647, 436-441.

10 G. Skorupskii and M. Dincă, J. Am. Chem. Soc., 2020, 142, 6920-6924.

11 B. Aurivillius and C. Särnstrand, Acta Chem. Scand. A, 1976, 30, 232-234.

12 C.-H. Wunderlich, R. Weber and G. Bergerhoff, Z. Anorg. Allg. Chem., 1991, 598, 371376.

13 R. K. Feller and A. K. Cheetham, Solid State Sci., 2006, 8, 1121-1125.

14 P. J. Saines, H. H. M. Yeung, J. R. Hester, A. R. Lennie and A. K. Cheetham, Dalton Trans., 2011, 40, 6401-6410.

15 L. Cooper, N. Guillou, C. Martineau, E. Elkaim, F. Taulelle, C. Serre and T. Devic, Eur. J. Inorg. Chem., 2014, 6281-6289.

16 G. Mouchaham, L. Cooper, N. Guillou, C. Martineau, E. Elkaïm, S. Bourrelly, P. L. Llewellyn, C. Allain, G. Clavier, C. Serre and T. Devic, Angew. Chem. Int. Ed., 2015, 54, 1329713301.

17 G. Mouchaham, B. Abeykoon, M. Giménez-Marqués, S. Navalon, A. Santiago-Portillo, M. Affram, N. Guillou, C. Martineau, H. Garcia, A. Fateeva and T. Devic, Chem. Commun., 2017, 53, 7661-7664.

18 T. Hidalgo, L. Cooper, M. Gorman, T. Lozano-Fernández, R. Simón-Vázquez, G. Mouchaham, J. Marrot, N. Guillou, C. Serre, P. Fertey, Á. González-Fernández, T. Devic and P. Horcajada, J. Mater. Chem. B, 2017, 5, 2813-2822.

19 E.-X. Chen, M. Qiu, Y.-F. Zhang, Y.-S. Zhu, L.-Y. Liu, Y.-Y. Sun, X. Bu, J. Zhang and Q. Lin, Adv. Mater., 2018, 30, n/a-n/a.

20 L. Cooper, T. Hidalgo, M. Gorman, T. Lozano-Fernandez, R. Simon-Vazquez, C. Olivier, N. Guillou, C. Serre, C. Martineau, F. Taulelle, D. Damasceno-Borges, G. Maurin, A. GonzalezFernandez, P. Horcajada and T. Devic, Chem. Commun., 2015, 51, 5848-5851. 
21 N. P. Power, S. J. Dalgarno and J. L. Atwood, Angew. Chem. Int. Ed., 2007, 46, 8601-8604. 22 R. M. McKinlay, G. W. V. Cave and J. L. Atwood, Proc. Natl. Acad. Sci., 2005, 102, 59445948.

23 K. Su, M. Wu, Y. Tan, W. Wang, D. Yuan and M. Hong, Chem. Commun., 2017, 53, 95989601.

24 A. S. Rathnayake, H. W. L. Fraser, E. K. Brechin, S. J. Dalgarno, J. E. Baumeister, J. White, P. Rungthanaphatsophon, J. R. Walensky, C. L. Barnes, S. J. Teat and J. L. Atwood, Nat. Commun., 2018, 9, 2119.

25 A. S. Rathnayake, H. W. L. Fraser, E. K. Brechin, S. J. Dalgarno, J. E. Baumeister, J. White, P. Rungthanaphatsophon, J. R. Walensky, S. P. Kelley, C. L. Barnes and J. L. Atwood, J. Am. Chem. Soc., 2018, 140, 15611-15615.

26 H. Kumari, A. V. Mossine, S. R. Kline, C. L. Dennis, D. A. Fowler, S. J. Teat, C. L. Barnes, C. A. Deakyne and J. L. Atwood, Angew. Chem. Int. Ed., 2012, 51, 1452-1454.

27 C. Zhang, R. S. Patil, T. Li, C. L. Barnes and J. L. Atwood, Chem. Commun., 2017, 53, 43124314.

28 K. Su, M. Wu, D. Yuan and M. Hong, Nat. Commun., 2018, 9, 4941.

29 A. S. Rathnayake, K. A. Feaster, J. White, C. L. Barnes, S. J. Teat and J. L. Atwood, Cryst. Growth Des., 2016, 16, 3562-3564.

30 R. M. McKinlay, P. K. Thallapally, G. W. V. Cave and J. L. Atwood, Angew. Chem. Int. Ed., 2005, 44, 5733-5736.

31 R. M. McKinlay, P. K. Thallapally and J. L. Atwood, Chem. Commun., 2006, 2956-2958.

32 H. Kumari, C. A. Deakyne and J. L. Atwood, Acc. Chem. Res., 2014, 47, 3080-3088.

33 D. J. Tranchemontagne, J. L. Mendoza-Cortes, M. O'Keeffe and O. M. Yaghi, Chem. Soc. Rev., 2009, 38, 1257-1283.

34 W. Kaim, Inorg. Chem., 2011, 50, 9752-9765.

35 S. Lee, K. Nakanishi, M. Y. Chiang, R. B. Frankel and K. Spartalian, J. Chem. Soc., Chem. Commun., 1988, 0, 785-786.

36 N. Stock, Micro. Meso. Mater., 2010, 129, 287-295.

37 M. R. Maurya, Coord. Chem. Rev., 2003, 237, 163-181.

38 N. E. Brese and M. O'Keeffe, Acta Cryst. B, 1991, 47, 192-197.

39 D. A. Dougherty, Acc. Chem. Res., 2013, 46, 885-893.

40 A. S. Mahadevi and G. N. Sastry, Chem. Rev., 2013, 113, 2100-2138.

41 A. Åhman and M. Nissinen, Chem. Commun., 2006, 1209-1211.

42 M. S. Marshall, R. P. Steele, K. S. Thanthiriwatte and C. D. Sherrill, J. Phys. Chem. A, 2009, 113, 13628-13632.

43 S. R. Cooper, Y. B. Koh and K. N. Raymond, J. Am. Chem. Soc., 1982, 104, 5092-5102.

44 M. Atzori, S. Benci, E. Morra, L. Tesi, M. Chiesa, R. Torre, L. Sorace and R. Sessoli, Inorg. Chem., 2018, 57, 731-740.

45 A. H. Jubert, R. P. Diez, S. B. Etcheverry and E. J. Baran, J. Raman Spectro., 1993, 24, 627631.

46 M. J. Sever and J. J. Wilker, Dalton Trans., 2004, 1061-1072.

47 C.-H. Hung, W.-T. Chang, W.-Y. Su and S.-H. Cheng, Electroanal., 2014, 26, 2237-2243.

48 C. Drouza and A. D. Keramidas, Inorg. Chem., 2008, 47, 7211-7224.

49 B. Baruah, S. Das and A. Chakravorty, Inorg. Chem., 2002, 41, 4502-4508.

50 G. Asgedom, A. Sreedhara, C. P. Rao and E. Kolehmainen, Polyhedron, 1996, 15, 37313739.

51 M. Shit, S. Maity, S. Bera, T. Weyhermüller and P. Ghosh, New J. Chem., 2016, 40, 1030510315.

52 S. Kundu, S. Maity, A. N. Maity, S.-C. Ke and P. Ghosh, Dalton Trans., 2013, 42, 45864601.

53 S. Kundu, S. Maity, T. Weyhermüller and P. Ghosh, Inorg. Chem., 2013, 52, 7417-7430.

54 P. Galloni, V. Conte and B. Floris, Coord. Chem. Rev., 2015, 301-302, 240-299.

55 M. Vlasiou, C. Drouza, T. A. Kabanos and A. D. Keramidas, J. Inorg. Biochem., 2015, 147, 39-43.

56 K. Muñoz-Becerra, P. Hermosilla-Ibáñez, E. Le Fur, O. Cador, V. Paredes-García, E. Spodine and D. Venegas-Yazigi, Cryst. Growth Des., 2015, 15, 2561-2564.

57 Kahn, Olivier, Molecular Magnetism, VCH, Weinheim, Germany, 1993.

58 P. Hermosilla-lbáñez, W. Cañon-Mancisidor, J. Costamagna, A. Vega, V. Paredes-García, M. T. Garland, E. L. Fur, O. Cador, E. Spodine and D. Venegas-Yazigi, Dalton Trans., 2014, 43, 14132-14141.

59 N. Ishikawa, M. Sugita and W. Wernsdorfer, J. Am. Chem. Soc., 2005, 127, 3650-3651.

60 Y. Sanakis, M. Pissas, J. Krzystek, J. Telser and R. G. Raptis, Chemical Physics Letters, 2010, 493, 185-190.

61 L. Tesi, E. Lucaccini, I. Cimatti, M. Perfetti, M. Mannini, M. Atzori, E. Morra, M. Chiesa, A. Caneschi, L. Sorace and R. Sessoli, Chem. Sci., 2016, 7, 2074-2083.

62 M. Atzori, E. Morra, L. Tesi, A. Albino, M. Chiesa, L. Sorace and R. Sessoli, J. Am. Chem. Soc., 2016, 138, 11234-11244.

63 'M. R. Maurya, Coord. Chem. Rev., 2019, 383, 43-81.

64 J. Guo, Y. Ping, H. Ejima, K. Alt, M. Meissner, J. J. Richardson, Y. Yan, K. Peter, D. von Elverfeldt, C. E. Hagemeyer and F. Caruso, Angew. Chem. Int. Ed., 2014, 53, 5546-5551. 
